\title{
Challenges and Approaches to Scaling the Global Commons
}

\author{
Felix Fritsch ${ }^{1}$, Jeff Emmett ${ }^{2,3 *}$, Emaline Friedman ${ }^{4}$, Rok Kranjc ${ }^{5}$, Sarah Manski \\ Michael Zargham ${ }^{2,3,7}$ and Michel Bauwens ${ }^{8}$ \\ ${ }^{1}$ Faculty of Political and Social Sciences, Scuola Normale Superiore, Florence, Italy, ${ }^{2}$ The Commons Stack, Zug, \\ Switzerland, ${ }^{3}$ BlockScience, Tempe, AZ, United States, ${ }^{4}$ Commons Engine, Ashland, OR, United States, ${ }^{5}$ FuturesCraft, \\ Ljubljana, Slovenia, ${ }^{6}$ University of California, Santa Barbara, Santa Barbara, CA, United States, ${ }^{7}$ Research Institute \\ for Cryptoeconomics, Vienna University of Economics and Business, Vienna, Austria, ${ }^{8}$ P2P Foundation, Amsterdam, \\ Netherlands
}

The re-emergence of commoning over the last decades is not incidental, but rather indicative of a large-scale transition to a more "generative" organization of society that is oriented toward the planet's global carrying capacity. Digital commons governance frameworks are of particular importance for a new global paradigm of cooperation, one that can scale the organization of communities around common goals and resources to unprecedented levels of size, complexity and granularity. Distributed Ledger Technologies (DLTS) such as blockchain have lately given new impetus to the emergence of a new generation of authentic "sharing economy," protected from capture by thorough distribution of power over infrastructure, that spans not only digital but also physical production of common value. The exploration of the frontiers of DLTbased commoning at the heart of this article considers three exemplary cases for this new generation of commons-oriented community frameworks: the Commons Stack, Holochain and the Commons Engine, and the Economic Space Agency. While these projects differ in their scope as well as in their relation to physical common-pool resources (CPRs), they all share the task of redefining markets so as to be more conducive to the production and sustainment of common value(s). After introducing each of them with regards to their specificities and commonalities, we analyze their capacity to foster commons-oriented economies and "money for the commons" that limit speculation, emphasize use-value over exchange-value, favor equity in human relations, and promote responsibility for the preservation of natural habitats. Our findings highlight the strengths of DLTs for a federated scaling of CPR governance frameworks that accommodates rather than obliterates cultural differences and creates webs of fractal belonging among nested communities.

Keywords: global commons, decentralization, distributed ledger technology, federated scaling, affordances

\section{COMMONING AS A REGENERATIVE SOCIAL PROCESS}

There is a substantial body of work that sees human history in its "thermodynamic context," attempting to understand the physical preconditions for the continuation of human societies (Turchin and Nefedov, 2009). These schools of thought generally hold not to an evolutionary conception of human history, but to a "wave-pulse" theory of human development, in which history is seen as a succession of waves between two polarities. The extractive polarity refers to class-based societies in which competing peer polities gradually over-use their regional boundaries, which 
leads to their collapse and a reaction toward the other pole, a more "generative" organization of society (Motesharrei et al., 2014) $)^{1}$ and (Whitaker, 2009) ${ }^{2}$. We posit that in this movement between polarities, the commons play a specific role in the regeneration of affected societies, and that such a worldhistorical situation is now occurring at the global scale. Our core introductory argument is this: Now that we have reached a planetary overshoot, it is time for the re-emergence of the commons as a conscious part of societal (re)organization. In this essay, we focus in particular on the emergence of a cyber-physical infrastructure (Bauwens and Pazaitis, 2019) that affords a global commons-based re-organization of production for human needs within local and planetary boundaries. Our key premise in this regard is that pooling resources facilitates collaborative engagement in the maintenance of common goods and dramatically reduces the human ecological footprint ${ }^{3}$ (Piques and Rizos, 2017).

In this manuscript commons are defined as institutions ${ }^{4}$ consisting of common-pool resources (CPRs) and the communities governing their use, maintenance, and reproduction through commonly devised and enforced rules. We refer to these processes of collective meaning-making as commoning. While natural resources, initially "common" but without protection from depletion, require institutionalization to persist as commons in the face of Hardin's (1968) tragedy, man-made $\mathrm{CPRs}^{5}$ in the digital and physical realm originate in processes of commoning - institutional embedment is their condition of existence.

The seminal work of Elinor Ostrom has shown that the commons are an institution well suited to equitably maintain a shared resource base in the long term (Ostrom, 1990, 2010), identifying both successful commons governance principles and the challenges associated with the practices of commoning and their global scaling (Ostrom et al., 1999). Building on this and other work, the digital nature of DLT technologies allows for novel, more generalized commoning patterns to be identified $^{6}$ (Hess, 2008; see also Schuler, 2008). This higher level of abstraction opens up the possibility to create replicable

\footnotetext{
${ }^{1}$ The HANDY study, i.e., "Human and Nature Dynamics" (Motesharrei et al., 2014) looks at human societies in a predator-prey framework, with the managerial classes playing the function of the predator, and the working classes playing the role of prey. In these studies, ranging back to the neolithic, at some point in a society's evolution the managerial classes overrun local resource limits, which eventually leads to collapse.

${ }^{2}$ The work of Mark Whitaker, who has produced a comparative review of 3,000 years of human history, focuses on three transition processes: in Europe after the fall of the Roman Empire, in Japan in the 12th century, and in China in the 15th century. Each time, an alliance between religious reformers and the population mobilizes around "ecological revolutions" that aim to restore harmony both within society and with nature.

${ }^{3}$ The case for this hypothesis is made by Piques and Rizos (2017), with a case study in agriculture showing a potential gain of $80 \%$ in the use of matter/energy usage.

${ }^{4}$ Institutions here are defined as "stable patterns regulating human behavior" (Zargham et al., 2020a) that can include commons, as well as market (private) or state (public) institutions.

${ }^{5}$ Our use of "resources" is not limited to naturally occurring commodities but also encompasses produced goods and infrastructure serving as input factors in further productive processes.

${ }^{6}$ For some preliminary discussions of a potential pattern language for the commons see Finidori (2014)
}

and customizable frameworks for commoning, focusing on similarities despite differences, and using digital "convivial tools" (Illich, 1973) to facilitate commoning practices among widely varying communities. Working with these meta-patterns creates opportunities for sharing highly technical governance and management techniques between commons-based movements while also maintaining a diversity of values. Accordingly, this paper examines new tools that allow resources and access rights to flow smoothly within and between federated, polycentric communities, creating new, and powerful leverage that could give commoning a stronger foothold against entrenched economic norms. In other words, these tools act as infrastructural bridges between islands of local commons that are adrift on a sea of global capitalism.

The historically dominant form of commoning pertained to the shared use of natural resources. With the emergence of capitalism $^{7}$ came their enclosure, especially of land commons that were an integral part of the life of the peasantry. These enclosures occurred before the beginning of the industrial revolution and are continuing as we speak in the countries of the Global South. In Europe, they forced massive numbers of farmers to migrate to the manufacturing cities of early industrial capitalism. Their misery led to the emergence of the social commons as the dominant form of commoning in the 19th century, i.e., the pooling and mutualization of risk. This places the history of the working class and the labor movement squarely in the history of the commons. But as the labor movement strengthened, the right to solidarity through social security became a right of all citizens, managed by the state bureaucracy or special public bodies. Thus we can say that as natural resource commons were privatized as productive assets of individual capitalists, the social commons were "stateified" in the form of public social security systems in the form of public social security systems in order to stabilize the unequal capitalist system. The latter was to a great degree a significant social progress; in the industrial countries, it meant a general protection of most of the population without the self-governance typical of a commons. This is how "commoning" may be said to have fallen out of favor as a core aspect of modern societies. It is in this context of the "forgetting of the commons" that digital networks emerge, and with them, a massive growth of commons of knowledge, software, and replicable design patterns.

The history of interconnected digital networks came in two significant phases. The first wave, which started in the late 1980s but came to fruition after the invention of the web and the browser in 1993, created a vibrant internet of communication, which created the possibility of peerto-peer (P2P) communication and organizing, including the production of immaterial resources such as free and open-source software and design. In the early 2000s, commons-based peerproduction (CBPP) of digital resources such as Wikipedia (Benkler, 2002, 2006; Fuster-Morell, 2010) and the P2P pooling

\footnotetext{
${ }^{7}$ We understand capitalism as an economic system based on private ownership of the means of production by the capitalist class, which maximizes surplus extraction from the working classes as the base of private capital accumulation. Conversely, post-capitalist imaginaries centered on the commons envisage an economic system characterized by equipotentiality and common capital accumulation that respects both social needs and planetary boundaries.
} 
of physical resources through early sharing economy sites such as Couchsurfing emerged as popular applications that outlined the potential of digital communication networks for commoning. Realizing the commercial potential of control over networks and exclusive access to data, a plethora of such networks were soon created by social media companies looking to extract surplus value from the affective and cognitive work of their users (Coté and Pybus, 2007; Fuchs, 2012; Beverungen et al., 2015). In many instances, this entailed the creeping (re-)introduction of capitalist relations under the cover of a resource-efficient "sharing economy," as for example Couchsurfing made way for Airbnb, or ride-sharing communities were replaced by Uber and BlaBlaCar.

The emergence of blockchain ushers in a second phase of digital networks: that of an internet of peer-to-peer transactions. If the first wave propelled stigmergic cooperation through mutual signaling, DLTs potentially create shared accounting ledgers around which open collaborative supply networks can organize the production of both material and immaterial goods and services. In a recent investigation, Rozas et al. (2018) explore this potential in the context of CBPP communities and highlight decentralization, use of CPRs, and a multiplicity of motivations beyond monetary value as core characteristics expressible through blockchain features. Beyond this principal fit, they identify a set of six affordances ${ }^{8}$ of blockchain technology that provide commoning communities with new impetus for self-governance, as seen in Table 1 below.

Although these affordances were identified in the context of immaterial production by digital CBPP communities, they just as well facilitate the digital governance of material production, which is what many see as the true transformative potential of DLTs (Christidis and Devetsikiotis, 2016; Davidson et al., 2016; Ulieru, 2016; Beck, 2018). In both cases, however, the direction of this transformation is still underdetermined: While the distribution of backends over multiple nodes decisively counteracts the (re-)centralization efforts pursued by the "netarchical class" (Bauwens, 2005) of digital platform entrepreneurs, the affordances identified here as serving commons-based ends can just as easily be put in service of "distributed capitalism" (Bauwens and Kostakis, 2014). In fact, performative struggles over the dominant narrative in the emerging institutional landscape are already raging between adherents of "crypto-libertarian" and "crypto-commonist" visions of a distributed economy (García-Siñeriz, 2018). The former, led by Bitcoin and recently joined by Ethereum's emerging "decentralized finance" (DeFi) environment, have

\footnotetext{
${ }^{8}$ Technical artifacts and their social embeddedness defy assumptions of unidirectional causality in the relation between technology and society as displayed by technological determinism, but also social constructionist absolutisms disregarding the specificity and unequal potential of particular technologies. Following Gibson (1979); Hutchby (2001), and Norman (2004), we understand affordances as socio-technical relations linking technical artifacts and their properties to potential social outcomes. They are mediated through individual disposition - aims, cognitive skills, knowledge - as well as through the cultural, socio-economic and political environment in which an artifact is produced and used. This relational framing emphasizes the subjective dimensions involved in recognition, interpretation and use of technical objects and their features, separating technological essence from its individual and societal reception, and highlights the importance of developing appropriate cultural protocols that emphasize the commoning potential of DLTs.
}

already received ample attention in academic literature and in mainstream media alike, thus shaping the public perception of cryptocurrencies as a hyper-capitalist technology used for speculation, tax evasion and trade of illicit goods and services. Early on, critical commenters such as Karlstrøm (2014), Kostakis and Giotitsas (2014); Atzori (2015), or Garrod (2016) have warned against the dire economic and political consequences of this vision of unfettered laissez-faire capitalism, highlighting both the macroeconomic need for accountable monetary policy and the intellectual poverty of the underlying hyperreductive social theory (see di Zerega, 2013 for an elaborate critique thereof). Crypto-commonist visions, on the other hand, have started to gain significant traction in academic literature and the cryptosphere ${ }^{9}$ itself only recently (e.g., Cila et al., 2020; Ducrée et al., 2020; Husain et al., 2020; Manski and Bauwens, 2020). This may be owed predominantly to the fact that commoning structures and value modes are typically much more complex to design than simple market functions and come with a range of challenges ${ }^{10}$. However, we contend that the predominance of hyper-capitalist cryptocurrencies also appears as a product of the naturalization of capitalist assumptions and the systematic concealment of alternative forms of production, access, ownership, management and innovation through ideological delusion.

The difficulty to consistently voice and popularize radical alternatives against the backdrop of an entrenched neoliberal hegemony shows not least in protracted theoretical struggles to come to terms with the commoning potential of DLTs

\footnotetext{
${ }^{9}$ Beyond the case studies, this includes projects such as Disco.Coop, Regen.Network, MetaGame, SourceCred, the Token Engineering Commons, and many more.

${ }^{10}$ Designing commons-oriented markets and community frameworks entails significant technological, economic, cryptographic, game theoretic, cultural, behavioral and psychological challenges that require concomitant consideration. While DLTs resolve the cryptographic challenge, meeting the others remains a crucial condition for the construction of balanced, safe and lively structures of interaction. In particular, the implementation of incentives and disincentives in geographically distant, "digital first" and trustless environments is prone to game-theoretic attacks to which designs must attend.
}

TABLE 1 | Blockchain affordances for commoning, per Rozas et al. (2018).

\begin{tabular}{ll}
\hline Affordance & Result \\
\hline Tokenization & $\begin{array}{l}\text { Entails "the process of transforming the rights to perform an } \\
\text { action on an asset into a transferable data element" (2018: 8) }\end{array}$ \\
$\begin{array}{ll}\text { Automated self- } \\
\text { enforcement of } \\
\text { rules }\end{array}$ & $\begin{array}{l}\text { Requires their formalization as explicit "input-output" } \\
\text { conditions in code, which shifts discretion into algorithmic } \\
\text { policy making itself, while the execution of that policy } \\
\text { becomes strictly deterministic }\end{array}$ \\
$\begin{array}{ll}\text { Autonomous } \\
\text { automatization }\end{array}$ & $\begin{array}{l}\text { Encourages the agglomeration of self-enforcing rules into } \\
\text { comprehensive structures that steer members' interactions } \\
\text { toward predetermined trajectories }\end{array}$ \\
$\begin{array}{l}\text { Decentralization } \\
\text { of power over } \\
\text { infrastructure }\end{array}$ & $\begin{array}{l}\text { Allows for communal ownership and control of commonly } \\
\text { used technology }\end{array}$ \\
$\begin{array}{ll}\text { Transparentization } \\
\text { Eodification of }\end{array}$ & $\begin{array}{l}\text { Encourages the open monitoring of decision-making and } \\
\text { community participation data }\end{array}$ \\
trust & in their enabling technical systems as well
\end{tabular}


and to reconceptualize markets outside of capitalist relations of production. While the recent proliferation of (self-defined) commons-oriented blockchain projects is a sign of the increasing popularization of commoning, it has resulted in an abundance of new takes on the matter that often lack the academic rigor to maintain definitional clarity. The resulting conceptual fuzziness among practitioners, compounded by rapid advances in technology, challenges existing theoretical schools in coming to terms with the specifics of DLT-based commoning ${ }^{11}$. Before visiting existing inconsistencies and disagreements as well as notable attempts at resolving them, a brief review of the different dimensions of DLT commons is deemed appropriate here, which too often remain implicit or are omitted altogether in the literature.

Since (public) blockchains and other DLTs are open source software, as a technology they belong to the broad field of digital CPRs, produced and maintained by open source contributor communities through processes of commoning. Their nature as a publicly usable and readable distributed database additionally renders them as infrastructure. Applications operating on top of DLTs in the form of open-sourced smart contracts are likewise digital commons and often constitute more specialized infrastructure commons than their underlying computational substrate. Finally, a growing number of DLTs and applications built atop are designed with the explicit purpose of being organizational infrastructure for commoning. This commoning may take the form of building and maintaining more technologies, but it also includes support for nontechnological commoning such as communal art projects or even governing communities whose activities and outputs manifest in the physical realm. These communities, like the (nondigital) volunteer organizations predating them, are driven by shared goals of producing and/or maintaining CPRs they ascribe value to. In fact, it is only this last dimension, the explicit orientation toward an aim external to money in and of itself, that differentiates crypto-commonist from cryptolibertarian approaches.

Voshmgir and Zargham (2019) and Voshmgir (2020) discuss Bitcoin as a prototype for a new form of CPR that comes about as a side product of the self-serving activities of profit-maximizing actors, the miners, and serves the circulation and accumulation of exchange value. Voshmgir (2020) in particular sees the popularization of this model of secondary production of CPRs in

\footnotetext{
${ }^{11}$ The same ambiguity that haunts the use of "commons' terminology in the context of DLTs can be observed with regards to Decentralized Autonomous Organizations (DAOs), a novel form of blockchain-enabled institution (Zargham et al., 2020a). DAOs are considerably under-theorized and underdefined, with everything from Bitcoin (Buterin, 2014) to investment clubs (e.g., VentureDAO) to off-chain communities such as Sensorica and Enspiral (Freund and Stanko, 2018) having been called so over time. In particular, it remains unclear what DAOs are supposed to be autonomous from - while Buterin (2014) theorizes them as being Automatons that are autonomous from human steering once incepted, the more recent use of DAO terminology instead implies that these organizations somehow grant their users (formal, but also de facto) autonomy from state and corporations - alas without basing this claim in credible conceptualizations of autonomy. Given this fundamental ambiguity, but also the fact that only one of the three projects compared in this article is concerned with building organizational infrastructure, we refrain from elaborating their potential contribution to commons-based economies here.
}

the slipstream of for-profit production (in this case, of "hashrate") as the most promising quest for commoners seeking to harness DLTs' affordances. Her research on "purpose-driven tokens" thus centers on the inscription of external purpose into competitive games in which the interplay of profit-maximizing individuals generates common use value. Primecoin, an algorithm that lets miners compete in the search for undiscovered prime numbers, is often referred to in this context as an exemplary case of a purposedriven token that produces a common good as a side product - a positive externality.

Such identification of the Bitcoin network and other DLTs as commons is controversial. Bauwens and Kostakis (2014) argue that rather than constituting a commons-oriented project geared to satisfy societal needs, the Bitcoin network is emblematic of a new, distributed kind of capitalism that utilizes peer-to-peer infrastructure for the generation of private profits. Kostakis and Giotitsas (2014) likewise challenge its characterization as a commons given its embodiment of "ideas drawn from a certain political framework" (2014: 437) - i.e., anarcho-capitalism based on the Austrian School of Economics - that promotes scarcity and competition and thus serves to aggravate rather than ameliorate the over-accumulation of capital and accompanying social inequalities that characterize the neoliberal era (Bauwens and Kostakis, 2014). Atzori and Ulieru (2017) further reference Bitcoin's "power law effects, where over time, disproportionate gains accrue to first movers through a process of preferential attachment," as reminiscent of "an industrial age economy which achieves value through scarcity and the ability to speculate" (2017: 5) and in effect only adds more rampant speculation and fraud to the platform capitalism with which we are all too familiar. More generally, they conclude that:

\begin{abstract}
"the Bitcoin-like model is wholly contrary to the way in which information, expertise and reputation build value individually and socially, ... since ... increased participation via value sharing that is the prerequisite to a real sharing economy ... would require cooperation attributes such as group identities, trusted identities as well as metrics and principles enabling sharing in a commons (Ostrom, 1990) to be embedded in the architectural protocols of the intermediary platform" (2017: 6).
\end{abstract}

In a similar vein, Volont and Van Andel (2018) agree in principle that blockchains potentially resolve matters of overuse, communication, and scale that stand at the core of Hardin's tragedy, and as such may facilitate "many new instances of commons, be they financial, peer-to-peer, or cultural" (2018: 3). However, in themselves, blockchains constitute a paradox to existing commons conceptions given their contested nature as "a market common, a monetary common, a kind of common that facilitates the accumulation of exchange value for, indeed, self-interested individuals" (2018: 1). Despite being horizontally organized, decentralized and belonging neither within the realms of centralized market nor state, the native protocol token at the heart of any public blockchain necessarily represents exchange value. In order to qualify as "real," uncontested commons, they conclude that blockchains must go beyond the expression of exchange value and be put in the service of use value production and circulation as well, which, "still, is where the commons begin" 
(2018: 6). However, to Volont and Van Andel, the probability of en masse reorientation toward the collective production and consumption of use value ultimately remains subject to an ideological battle between competing narratives over norm and exception that cannot be resolved through technological innovation in itself.

A remarkably different way to accommodate the paradox Bitcoin and other crypto-libertarian projects pose to preexisting conceptions of the commons is to discard implicit romanticist assumptions casting all commons in revolutionary terms and instead to differentiate between pro- and anti-capitalist commons. Autonomist and post-autonomist scholars such as Hardt and Negri (2011); Caffentzis and Federici (2013), or De Angelis (2017) have lately embraced the commons as a core facet of anti-capitalist struggles, going so far as to consider them "a possible source of a new social model organized around sharing and voluntary participation" (Arvidsson, 2019: p. 3). However, like-minded scholarship has also highlighted how in post-Fordism, capitalism not only plunders, but increasingly also creates and nurtures commons in order to exploit their spoils as long as they ultimately remain productive of exchange value further down the line. Examples include the infiltration of the free open source software movement by dominant market actors in order to outsource developing costs to volunteers while steering the results into more productive trajectories (Bauwens, 2005 and Bulajewski, 2011), the business model of social media and "sharing economy" platforms that present themselves as social or communication commons while siphoning off surplus value their users generate as free labor (Terranova, 2000) through interfaces designed to maximize the consumption of advertisements (Friedman, 2020, or NGOs that nurture local urban commons in the service of real estate capital siphoning off the surplus of gentrification (Hardt and Negri, 2011; Weber, 2017). In this light, crypto-libertarian projects that first and foremost serve the accumulation of exchange value may well be considered commons, but pro-capitalist commons that reproduce and exacerbate economic inequality while stalling any truly transformative potential. Crypto-commonist projects, on the other hand, could be considered anti-capitalist insofar as they seek to challenge central mechanisms of capitalist accumulation, namely private ownership of the means of production, competition over market share that leads to monoor oligopolies, or one-directional condensation of information into exchange value.

So far, reviewed scholarship has insisted that the "real," uncontested, non-capitalist type of commons revolves around the provision of use value, that is, some systems-level purpose other than the circulation and accumulation of abstract exchange value, to members of a community or to society at large. Conventionally, this entails the production of goods and services for the satisfaction of needs rather than for sale on a market. However, under a value sovereign monetary regime, (use) values other than profit can also be directly inscribed into the calculus of exchange value. Freund and Stanko (2018) refer to this phenomenon as a critical aspect of "decentralized socioeconomic markets," and further characterize the latter as markets that differentiate internal production and compensation arrangements from external market interfaces and contain means of setting agendas for production collectively. Decentralized socioeconomic markets also configure infrastructure primarily to serve the efficient fulfillment of individual, societal and ecosystemic needs through the circulation of contextually differentiated goods and services, and considers the effects of production on others (i.e., internalizing what capitalist markets consider to be "externalities"). In line with Table $\mathbf{1}$ above, they find that blockchains support the rise of decentralized socioeconomic markets by affording enhanced capacity to transparently account for many different forms of value based on participant acknowledgment and agreement, and to enforce fair, reciprocal distribution of profits through technical means:

"[W]e are now able to programmatically not only provide an open, censorship resistant, and tamper proof value accounting system, but are also able to freely define and value assets based on perceived value by participants. In addition, we can define programmatically enforced rules around asset usage and exchanges such that, for example, the monetization of an open source project from a decentralized economy is appropriately shared with the producing common. This ensures reciprocity between asset user and creator." (Ibd.: 33)

Decentralized socioeconomic markets therefore defy the organizing principle of capitalist markets, which involves creating goods and services strictly according to their profitability, favoring the existence of market entry barriers, fostering informational asymmetries, and encouraging high local product differentiation ("monoculturalism"). These three traits signify a high but limited degree of competition over market share, as well as a means of exchange that omits information on externalities that do not lend themselves easily to commodification. Yet, the degree to which markets can or should be used to coordinate the commons at all depends upon one's convictions about the market form and whether or not it can be used to subvert unfettered accumulation of exchange value: do markets necessarily involve the exploitation, inequalities, and privileges that are so apparent at present, or are these pitfalls attributable to some confounding or inessential component of markets today?

One answer to this question comes from left wing market anarchism. This tradition draws on Proudhon's use of contract and exchange for social mutuality to posit the essential features of markets "freed from government and capitalist privilege" as follows: ownership of property (especially decentralized, individual ownership), contract and voluntary exchange (with the expectation of mutual benefit), free competition (without pre-established restrictions or barriers to entry), entrepreneurial discovery (of new opportunities for socioeconomic benefit), and spontaneous order (where decentralized negotiations, exchanges, and entrepreneurship gives rise to large-scale coordination beyond any deliberate plans or common blueprint) (Chartier and Johnson, 2012: p. 2; see also Proudhon, 1851). Left wing market anarchists reject the belief (common both to the anti-market left and the pro-capitalist right) that these features must entail a social order of bosses, landlords, centralized corporations, and class exploitation, essentially attributing the radically unequal character of markets under capitalism to entrenched political 
privilege and authoritarian legal systems (ibid). Albeit in less overtly ideological terms, this argument is shared by Arvidsson (2019: p. 5), who, reiterating Braudel's (1984) and Marx' (1867/1976) work on pre-capitalist market structures that are characterized by their "small-scale and egalitarian nature and [their] vicinity to the social fabric - to the longue dureé of everyday life," holds that:

\begin{abstract}
"Markets are universal in recorded history, going back at least as far as the origins of urban civilization. Capitalism is more recent, and is usually imposed "from above" in some way, mostly via the exercise of state power. This perspective opens up for the possibility of non-capitalist markets." Arvidsson, 2019: 4)
\end{abstract}

Moreover, the degree to which markets serve the dictate of the capitalist class rests not only on legally sustained privilege, but also on the compression of information on needs and their satisfaction into prices, which omit distinctions between different needs in different contexts. In this regard, nation-state issued currencies appear as a key means for states to enforce capitalist privilege. Especially considering the massive quantities of behavioral data now collected, and possible to collect, on users, consumers, and citizens, it would seem that there are more fine-tuned, democratic ways of determining needs, wants, and concrete social benefit. Therefore, the notion of a market divorced from capitalist imperatives also requires a new kind of money for the commons. It is precisely this potential that many see in cryptocurrencies and blockchain technology (Srnicek and Williams, 2016; Arvidsson, 2019). Braga (2019) further qualifies these conditions in a review of the 2014 symposium "Money for the Commons," noting agreement amongst scholars that such a currency for the commons needs to be anti-speculative, not scarce, and operated on a technological infrastructure that minimizes energy expenditure.

So far, we have reviewed the historical trajectory of the commons in relation to nature and society as well as recent theoretical struggles to come to terms with an emerging new class of DLT-based commons frameworks that challenge conventional conceptions of commons through the use of markets outside of capitalist relations of production. While we deem orientation toward use value generation and active prevention of speculation and other extractive strategies essential to any commoning agenda, we are particularly interested here in the novelty DLT commons have brought to the fore in terms of inscribing such external aims into exchange value itself. As we will see in the next section, this combination of abstract and concrete value forms opens up opportunities for scaling networks of commonsoriented communities beyond the local and immediate while retaining value sovereignty for participants.

\section{LIBERTARIAN AND COMMONIST INTERPRETATIONS OF SCALE}

Rozas et al. (2018) have made the case that DLTs offer novel affordances to facilitate commoning based on Ostrom's eight criteria under which CPR management can be successful. In this section we move beyond assessing the principle fit of
DLTs for commoning to examining how they can be used to address some of the challenges in proliferating commons-based solutions to global issues. In particular, we will consider how the novelties DLTs introduce affect the capacity of commonsbased solutions to scale beyond the local, and how the "federated" scaling of commons differs from the monolithic notion of scale Silicon Valley has coined throughout the last decades. Furthermore, we inquire into the conceptual heuristics put forth by both crypto-libertarian and crypto-commonist interpretations of scale. In doing so, we complete the analytical framework along which we will then interrogate three cases of DLT-based commoning frameworks in order to flesh out their potential to move the commons from the margins toward the center of economic conduct.

While Ostrom is widely known for identifying common rules guiding successful CPR management worldwide, she also studied the challenges commons-based solutions face in scaling to address global problems such as climate change and biodiversity loss. In their paper Revisiting the Commons, Ostrom et al. (1999) identified six such challenges: Scaling up (1) faces increasing coordination costs of rule setting and enforcement that replace informal social exhortation with growing group size. While potentially increasing the capacity and resilience of communities, cultural diversity (2) additionally increases the difficulty of coming to terms among and between groups over shared resources. Mutual dependencies between interlinked CPRs (3) further complicate their management as they combine into complex systems that require coordination in use and governance. Accelerating rates of change (4) that derive from increasing population growth, economic development, mobility of capital and labor, and technological change increase the stakes of these challenges even further. The requirement of unanimous agreement (5) among states as the prevalent collective-choice rule to address global issues makes the quest for multilateral agreements extremely tedious and prone to either deadlock or extensive cherry-picking that undermines effectiveness. Finally, the fact that we have only one globe with which to experiment (6) underscores the slim margin for error in seeking alternatives.

These challenges can be broadly categorized into two groups: On the one hand, issues of scaling, cultural diversity and interlinked CPRs appear as restrictions that limit the potential for given commons-based responses to mitigate the depletion of global resource pools. On the other hand, accelerating rates of change and the fact that we have one globe to "experiment" with leave only a small margin for error in the high stakes environment imposed by our interconnected world. They create a strong sense of urgency to overcome said restrictions, but appear less as problems in themselves than as ideological premises that drive projects to solve the more tangible first three challenges. Finally, the need for unanimous agreement among nation states rather appears as a hindrance to state-focused responses (insofar as nation-states compete against each other) and thus as a part of the reasoning for commons-based alternatives. We will thus focus on the first three challenges, integrated under a comprehensive understanding of "federated scaling" that incorporates rather than obliterates cultural heterogeneity and 
remains attentive to non-linear dynamics between interlinked CPRs on different scales.

When seeking to scale DLT-based commons governance frameworks, it is crucial to differentiate the underlying technical dimension of scale that pertains to ICTs from the social dimension of scale that concerns communities built atop that infrastructure. Scaling the technical "backend" of commoning regards the database in which individual contributions, interpersonal interactions and collective decisions are recorded. It tends to follow the conventional notion of scaling as applied by Silicon Valley, which primarily ${ }^{12}$ revolves around adjusting a system to handle more and more workloads costefficiently. The most straightforward way, vertical scaling up, implies operating the system in question from a more powerful machine that has higher throughput capacity. However, as the marginal costs of scaling one central machine soon approach prohibitive levels, horizontal scaling out, the distribution of workload over several instances that work on different tasks in parallel, is often more feasible. As Gismondi et al. (2016) point out, the underlying notion of scale is deeply mechanical, profit driven and logically centralized and as such represents the standardizing tendency of 20th century Fordism. Arguably, this logic also pertains to blockchains ${ }^{13}$, which strive to incorporate ever more socio-economic relations through their standardization and adoption, despite the distribution of power over infrastructure upon which they are premised.

The number of transactions a blockchain can operate per second as the dominant benchmark for scale remains one of the main hindrances to mainstream adoption to date. While blockchains embody distributed architecture by default, the distribution serves security through redundancy but not efficiency through parallelization of tasks, and constitutes a major bottleneck in terms of increasing the number of transactions per second. Both scaling up and scaling out ${ }^{14}$ are challenging endeavors under these circumstances. Scaling up a blockchain either requires a collective shift of mining activity to supercomputers, which contradicts decentralization due to expensive hardware requirements, or incremental software refinement, which is slow, tedious and always risks fragmentation of communities. Examples are "Proof of Stake" and "Delegated Proof of Stake" protocols, which significantly increase throughput and reduce power consumption (Ducrée et al., 2020). These potential scaling solutions both require more complex gametheoretic security analysis than conventional Proof of Work protocols and have been subject to intense community debate

\footnotetext{
${ }^{12}$ More comprehensive considerations of scale in the context of DLTs also encompass technical interoperability with other DLTs in terms of the ability to share information as well as the existence of supportive infrastructure such as distributed data storage, oracles integrating off-chain events or user agents such as wallets and blockchain explorers.

${ }^{13}$ The recent development of non-blockchain DLTs has sought to overcome architectural obstacles to scaling efficiently. Given the wide range of potential solutions, their implications and limitations, we refrain from discussing them here in detail in order to instead remain focused on the difference and interrelations between scaling DLTs and scaling governance frameworks for commons.

${ }^{14}$ For an understanding of how these differ technically, see https://cointelegraph. com/explained/vertical-and-horizontal-blockchain-scaling-explained (accessed 15.09.2020).
}

throughout the last years. Scaling out on the protocol layer, on the other hand, risks undermining the security architecture of trustless distributed systems as it reduces redundancy and thus the power needed to corrupt any single task. Nevertheless, "sharding" denotes the attempt to scale out on the protocol layer while mitigating the incurred security loss through obfuscation of the partition lines (Singh et al., 2020). Other approaches to harnessing the benefits of scaling out are optimistic rollups or zero-knowledge rollups, which seek to inherit the security properties of the underlying, unpartitioned layer 1 protocol while significantly increasing throughput via partition on a higher layer ${ }^{15}$.

Issues of technical scale discussed so far drastically differ from the considerations encountered when seeking to scale communities that are limited in growth predominantly by the social contingencies of interpersonal trust and socioeconomic solidarity. Interpersonal trust, originating in established social relations, protects against excessive free-riding amongst peers, but is often lacking in larger communities, which instead revert to formalized rule sets that require monitoring and enforcement to be effective. While such formalization enables socioeconomic solidarity on a larger scale, it also increases administrative costs and undermines equality through introduction of a core bureaucracy, which reduces the overall appeal of commoning as a social practice.

Some DLT projects approach the question of trust by focusing on the emancipatory possibilities of "self-sovereign identity." The word sovereignty refers to "a general recognition of exclusive domain and consequent possession of the capacity to establish the rules of conduct within a particular field of action" (Manski and Manski, 2018). Individual users and organizations participating in multiple commons require self-sovereign infrastructure to set the boundaries regarding who has access to their data. This infrastructure thus allows people to protect their privacy and maintain autonomy while conducting joint work for collective action. As such, it constitutes a fixture of enabling transition from capitalist systems of private reward to commonsbased provisioning systems of inclusivity and belonging. Selfsovereign infrastructure is also a key point of contention between the crypto-commonist and crypto-libertarian visions, with the former looking to strong reputational anchoring to solve the commons-governance problem of free-riders and the latter focused on preserving the freedoms associated with anonymity ${ }^{16}$.

Rozas et al. have shown how the affordances of DLTs can be utilized in the governance of commons to "increase the degree of formalization of their processes to provide higher degrees of legitimacy, transparency and trust" (2018: 22). Automated self-enforcement of rules greatly reduces their costs

\footnotetext{
${ }^{15}$ See docs.ethhub.io for details (accessed 02.11.2020).

${ }^{16}$ Self-sovereign identity (SSI) and reputation systems are highly complex areas of discussion in themselves. Besides being hard to construct and bootstrap, SSI systems on their own are insufficient for commons due to root-of-trust problems (De Oliveira Nunes et al., 2020). The subjectivity and tradeoffs inherent in the design of the necessary graph structures to support these trust networks is evidenced by research into the SourceCred algorithm (Zargham, 2019). The Commons Stack proposes the inclusion of a reputable community called the Trusted Seed to initialize new community economies (Emmett and Green, 2019).
} 
and increases their efficacy while precluding the risk of an emerging bureaucratic elite. Tokenization and transparency of recorded contributions allow better control against free-riders and bring to the fore all different kinds of work necessary to collectively govern a commons. The decentralization of power over infrastructure and the highly granular nature of decision making DLTs enable further serve to increase the control participants have over pooled resources and shared infrastructure as well as over the trajectory a commons takes over time. All these affordances potentially contribute to more stable, legitimate and trusted governance structures that empower commons to grow beyond their current scale.

Nevertheless, there remain limits to the scale any individual commons can obtain. Contrary to abstract machines of economic value circulation and accumulation, individual commons have natural boundaries set by the needs of their constituents, beyond which they simply need not scale. As emphasized in the introduction, we define a commons by its orientation toward the provision of concrete use value, which reflects unfulfilled needs of its recipients and is thus necessarily contextual and limited. Or, as Arvidsson has put it succinctly: "On the commons things become valuable to the extent to which they can contribute to the distinct goals and aims that are inherent in the process of commoning that sustains them" (2019: 6). This also holds for addressing global problems such as climate change or biodiversity loss, which commoning strategies aim to meet through context-sensitive responses instead of the neoliberal practice of scaling monolithic solutions. In fact, it is precisely in making such sovereign yet interrelated initiatives communicable at the level of foundational protocols that we identify the greatest capacity of DLTs to tackle aforementioned global problems. This regards both the coordination of explicit relief efforts that channel labor and capital toward resolving perceived ills, and a shift from extractive to regenerative forms of production that voluntarily internalize the social, economic and ecological externalities they produce.

The concept of scale that underlies this vision is distributed in this paper we propose the concept of "federated scaling." Instead of either scaling up one central approach, as would be resembled by a UN-mandated global initiative against climate change, or scaling out one "best practice" approach to a coalition of nation states, federated scaling is conceived as a process of integrating heterogeneous forms of collective action into a framework that allows them to collaborate while acknowledging their interrelations and differences, and to formally account for them through shared expressions of value and structures of mutual stake-holding. It shares this inclusivity with the notion of wide and deep scaling (Moore et al., 2015; Olsson et al., 2017), which proposes a shift away from the global dominance of the cultural exports of a handful of U.S. tech companies and toward agnostic protocols that facilitate the peaceful coexistence of heterogeneous cultures and the resolution of conflict through community-based dispute resolution tools. In this light, we position federated scaling as a broader social and political economic transformation project that conceptualizes the commons and their value orientations as an example of counterhegemonic prefigurative politics. In so doing, it recognizes the questions of scale, scaling and scalability hinting at a much broader range of questions, namely, the assumptions, theories, strategies and mechanisms - in essence, the politics of and for change.

To conclude by returning to our entry point, that is, utilizing DLTs in order to resolve Ostrom's challenges to meeting global challenges through commons governance, the concept of federated scale highlights how commons-based responses can be scaled while preserving cultural diversity and accounting for mutual dependencies of interlinked CPRs. This social conception of scale crucially differs from technical scale as discussed at the outset of this section as it seeks to accommodate rather than abstract from heterogeneity. Technical scale appeals to libertarian interpretations that ultimately see the purpose of common DLT infrastructure in increasing the circulation of exchange value. In this context, scale is indicated predominantly by manageable workload as the basis of potential accumulation, and scaling can be applied to one monolithic structure that administers ever more transactions per timeframe. Crypto-commonist scaling, on the other hand, has to be federated because use value as "[t]he logic of value of the commons is ... based on singularity rather than equivalence" (Arvidsson, 2019: p. 6) and cannot be regressed into the one-dimensional metric of abstract exchange value without losing the meaning it is given by its respective community.

\section{EXPLORING THE FRONTIERS OF DLT-BASED COMMONING}

The inherent complexity of social systems interlinked with CPRs requires that approaches to understand and improve them limit their focus to specific aspects thereof. This also reflects in the projects introduced in this section - while broadly aiming at the shared problem of under-provision and protection of common resources, they approach it from different angles, and have different foci, blind spots, and potential areas of complementarity.

Their selection among emerging organizations centering on decentralized, peer-to-peer networks is based on their explicit aim to organize and govern material and immaterial commons through the novel aspects of DLTs referenced above (tokenization, automated self-enforcement of rules, autonomous automatization, decentralization of power, transparentization, and codification of trust). Moreover, they share an ideological commitment to creating market-like structures that do not rely on the axiom of capitalism to maximize shareholder profits. This commitment is important given the early stages of formalizing and acting upon the intention to apply DLTs to enable scaling and proliferating commons. This nascency furthermore warrants that these projects are taken into consideration more as detailing intended patterns and frameworks and less as deployed implementations. Many of their concrete use cases are intentionally left open as to allow for their customization in different contexts. In order to acknowledge these constraints and explore the diversity of approaches, we first examine each project on its own terms, before jointly discussing their approaches to markets, scaling, and the inscription of external aims into exchange value. 


\section{The Commons Stack}

The premise of the Commons Stack ${ }^{17}$ is to realign incentives around the provision of public goods in order to overcome the tension between individual and common interest that is at the core of existing limitations to commoning ${ }^{18}$. The proposed solution is a tool kit of computational constitutional patterns, with reference implementations developed as customizable open source modules that can be deployed on different DLT architectures such as Ethereum, Holochain or EcSA. This toolkit facilitates funding, governance over CPR allocation, retrospective and real-time data-driven analysis as well as prospective modeling and simulation of commons-oriented DAOs. In particular, it introduces bonding curves as a new tool for collective preference estimation and shared resource allocation (Zargham et al., 2020b,c), which act as semi-permeable value transfer interfaces that can be designed as a more responsive and representative way to pool communal funds for the provision of public goods.

Their economic module, the Augmented Bonding Curve $(\mathrm{ABC})$, is an automated market that facilitates the trade of governance tokens through minting and burning according to demand and a deterministic price structure, while continuously feeding a common pool of funds through taxation of said trades. The interplay between the interests of token holders (a) to sell when token price rises and (b) to buy as price drops to claim additional governance power over a growing treasury, creates a negative feedback loop that leverages speculative behavior into a continuous source of income for the project. This application of bonding curves as the political-economic boundary of a commons is a novel concept, with the overall system being "augmented" by the introduction of continuous funding for communal resources, with governance over those funds being controlled by the issued token. By paying out work done in the community in its native token, this design aligns the incentives of workers and providers of capital in a collective agreement of stewardship based on contributions of both capital and labor. By correlating the spot price of tokens with their quantity in circulation through the bonding curve, a speculative profit potential opens that rewards successful commons stewardship, leading to more participation in the shared cause and incentivizing early participation in promising

\footnotetext{
${ }^{17}$ See https://commonsstack.org (accessed 05.01.2021) as well as an in-depth case study by Fritsch (2020).

${ }^{18}$ Incentive systems need careful design and consideration, as attested by Goodhart's Law (Graham, 2020). With the potential for unintuitive effects like financial incentives crowding out other useful social motivations (Freund, 2018), we can expect that simplistic incentive systems alone will fail to encourage appropriate behavior. However, incentive structures can also be embedded in second-order cybernetic systems (von Foerster, 1995/1974) that allow for their rapid and dynamic evolution in case of revealed game-theoretic attack vectors or other unforeseen consequences. If furthermore supported by tools for ComputerAided Governance (Emmett and Zargham, 2019) that aid communities in understanding the systemic impacts of potential mediations, these systems become more robust to the failures of static incentive structures and their unintended consequences. While much of this remains prefigurative, recent experiments conducted not only by the Commons Stack, but also by ixo, PrimeDAO, SourceCred and 1 Hive represent early attempts at shifting from static to dynamic models that better incorporate change into their continuous evolution.
}

communities. At the same time, as market interaction with the $\mathrm{ABC}$ increases, the community funding pool benefits from additional tax revenue.

The Commons Stack innovates in terms of mechanism interoperability, allowing maximum customization of governance processes as decided on a community by community basis. In addition to the potential for one-identity-one-vote systems, they also explore non-linear decision-making tools that significantly alter traditional voting processes. "Conviction Voting" (CV) mediates voting power by the amount of time a preference has been held stable, thus preventing last minute vote swings by large token holders, while "Quadratic Voting" $(\mathrm{QV})$ is a planned future component that discounts the weight of votes by an exponential function to more prominently value minority opinions. The inclusion of these mechanisms is an attempt to moderate voting power in token-based governance systems, both in space (in the case of QV), and in time (in the case of $\mathrm{CV}$ ). The former reduces the relative impact of large token holders, the latter more fundamentally changes decision making toward continuous preference signaling, thus facilitating real time indicators of collective sentiment. The use of these novel tools in governance requires specific customization to community context, and thorough modeling and design to protect against known and unknown attack vectors $^{19}$.

To mitigate possible system failures, the Commons Stack combines agent-based and holistic system modeling to simulate the specific parametric configuration and combination of modules. This modeling is carried out using a new open source data science tool called cadCAD, short for complex adaptive dynamics Computer-Aided Design, developed by the Commons Stack's partner firm BlockScience. cadCAD's analytical capacity to simulate and ward against unsustainable systemic developments becomes increasingly important with the growing complexity of the system under scrutiny. This becomes even more relevant when multiple systems administrating CPRs, each with their own rules and dynamics, are interlinked to form networks of networks. Following the established practice of complex systems engineering, these models also act as a digital twin (Voshmgir and Zargham, 2019), which provides members with a means of simulating the prospective impacts of future governance decisions in the style of "Computer Aided Governance" (Emmett and Zargham, 2019).

Underscoring the need for DAOs to move beyond being mere technical solutions applied to social problems, the Commons Stack places further focus on the cultural aspects of DAO governance with the introduction of the "Trusted Seed." This community acts as a trusted pool of knowledgeable stakeholders who can be invited to help launch independent "Commons" that

\footnotetext{
${ }^{19}$ Detailed analysis of the parametric design space and the implications of Conviction Voting for community governance processes as well as of potential exploits is provided by Fritsch (2020), who discusses this tool in the context of contemporary forms of algorithmic governance as well as of Autonomist forms of collectivity based on voluntarism and direct action. A cadCAD model of Conviction Voting, developed by the research firm BlockScience, can be found at https://github.com/BlockScience/Aragon_Conviction_Voting (accessed 02.11.2020).
} 
use the Commons Stack toolkit, with the intention of ensuring that initial participants are more interested in the long-term health of the ecosystem than in short-term profit extraction.

\section{Holochain's Commons Engine}

The Commons Engine ${ }^{20}$ is a service organization dedicated to the design and implementation of currencies (or current-sees; denoting the flow or current that one wishes to make visible) built using the post-blockchain DLT, Holochain ${ }^{21}$. Holochain is a highly scalable, agent-centric ${ }^{22}$ (and thus sovereign-identityprioritizing) framework for writing distributed applications. Elinor Ostrom's principles for commons governance continue to guide the data ethics of Holochain. Innovating in areas like open source licensing ${ }^{23}$, the Holochain community understands that the pooling of data tied to particular agents and entities requires special protections for user-participants and the design of "membranes" necessitating reputation systems. As the ethics of FOSS resonate deeply in these loose groups, value-accounting initiatives like Co-makery ${ }^{24}$ use already-existing blockchainbased tokens to track and reward contributions for the ongoing development of core functionalities that can be used across currencies and communities.

The Commons Engine's approach to currency design lauds a few principle mechanisms: asset-backing and mutual credit. In their simplest form, asset-backed currencies appear as direct representations of the resource, good, or service they track and modulate. They aim to disentangle the two most contradictory functions of money, acting as a store of value and a medium of exchange. The strong monetary "store of value" function fulfilled by Bitcoin and other speculative crypto currencies contradicts their "medium of exchange" or final settlement function by relying on fixed supply and thus scarcity, while their volatility voids any function as a unit of account. This contradiction is resolved by inscribing not only a particular use value but the temporality of that use value into an array of asset-backed currencies. Doing so has the effect of sorting currencies into exchange media (e.g., food and treated water) and value stores (e.g., wood, homes, and identity). One could envision how this approach is suited well to a multi-currency constellation of use values and temporalities. Asset-backed currencies are particularly important for helping communities track, modulate, and extend access to universal human basics like food, water, energy, and housing. They emphasize sufficiency over growth, and help protect against speculation and hoarding because their value is

\footnotetext{
${ }^{20} \mathrm{https} / / /$ commonsengine.org (accessed 05.01.2021).

${ }^{21} \mathrm{https}$ ///holochain.org (accessed 05.01.2021).

${ }^{22}$ While blockchains are state centric systems that have one central public ledger, agent centric systems allow for the creation of nested network structures in which each network has its own ledger tracking relations between participants, and programmable informational boundaries regulate its perception from the outside. There is no central state that subsumes all others but rather a distributed network of states that can never be perceived in its totality but only partially, from individual perspectives (Brock, 2017).

${ }^{23}$ In 2019, a Holochain-associated hosting company, Holo, published the Cryptographic Autonomy License as a Commons Attribution-ShareAlike 4.0 International License. See https://opensource.org/licenses/CAL-1.0 (accessed 14.05.2020).

${ }^{24} \mathrm{https} / / /$ www.comakery.com/(accessed 14.05.2020).
}

tethered to the utility of the underlying asset and its real world price at the point of purchase.

In the case of JustOne Organics ${ }^{25}$, an organization that dries local farmers' seconds for long-term shelving, a foodbacked currency called JOOLES is directly exchangeable for "gently dried" fruits and vegetables. This asset-backed currency is used in conjunction with a coupon that helps fund drying centers that become food "hubs" in different communities to grow their levels of resilience through food security. And yet, the currency is simply a pre-purchase of food. In the future these currencies aim to tie measures like nutrition density of soil or amounts of carbon sequestered by participating farms into the currency itself, meaning that value is derived not from its scarcity as it might be in a general, monetary currency, but from the underlying asset's capacity to enrich and extend human life within the Earth's natural boundaries. Here, currencies act also as impact assessment tools that track human wellbeing and ecological regeneration to direct collection action to counteracting or accommodating what capitalism still deigns to consider "externalities."

Another crucial mechanism for designing currencies is mutual credit accounting (Greco, 1994). Mutual credit accounting requires the balancing of credits and debits such that the combined balance of all accounts sums to zero. Credits in such a system are only issued upon the actual sale of a good or service, with those credits being destroyed when those goods or services are fully reciprocated. Many issues commonly associated with monetary policy do not apply in mutual credit systems, the credit supply of which is inherently tethered to the economic capacity of the network without guesswork or speculation. Governance of mutual credit systems hinges primarily on the credit limits assigned to different accounts with their different reputations and histories. Relevant measures might include the size of past annual sales, whether the account holder has rendered the services or performs duties it promises in a timely fashion, in the manner promised, if they are known to settle balances late, or if they have also provided a governmentissued form of identification. Determining these parameters of what constitutes reputation and identification that matters in the producing commons require democratic decision-making processes, attentiveness to the constraints and liabilities under relevant jurisdictions, and refinement of reputation systems relative to particular communities and their goals to better align with collective determinations of needs and aims.

\section{Economic Space Agency}

The Economic Space Agency (ECSA) ${ }^{26}$ puts capitalism itself up for debate as it sets out to re-imagine markets, price and profit in cooperative terms. Its vision of digital economic networks as intentionally designed spaces that have social values beyond profit directly inscribed into the protocols of interaction is a structural and highly generic interpretation of commons ambitions that, crucially, remains agnostic to the choice of common values to be inscribed in these networks. While in

\footnotetext{
${ }^{25}$ https://justoneorganics.com/ (accessed 14.05.2020).

${ }^{26}$ https://economicspace.agency (accessed 05.01.2021).
} 
their capitalist shape, protocols such as markets, pricing and profit making may be oriented toward private property and self-interest, ECSA claims that they could also meaningfully be redesigned as "spaces of exchange" to serve shared social values such as "human rights, working conditions, income distribution, environment, social impact, etc" (Bryan et al., 2019). Accordingly, ECSA's comprehensive post-blockchain tech stack is designed to empower networks of agents to develop and deploy protocols of interaction that uphold the values they share in specific contexts.

Going beyond the disintegration of singular exchange value into multidimensional value metrics, money itself is replaced by a faceted token system that treats decentralized exchange, P2P credit issuance and clearance, multidimensional performance measurement and distributed ownership as distinct protocols. In this system, commodity tokens serve as transferable representations of goods, services and other assets, which are created as assets on the one and liability on the other side of a trade once a match is made between offer and acceptance, and cleared once the actual commodity is transferred. Based on trust in one another, economic actors can issue liquidity tokens to peers in order to bridge time differences between offers and acceptances and thus facilitate economic business cycles in the absence of banks providing liquidity. Finally, stake tokens are issued upon investment in individual as well as composite performances of economic actors as well as in the overall performance of any single Economic Space, thus reflecting exposure to the up- and downside potential of others' economic activity.

Economic Space Agency's notion of performances as causal relations between economic events and their contingent outcomes is intentionally broad. It allows the creation of derivatives covering the widest possible range of events, measuring their economic outcome against a predefined index and thus turning them into tradeable forms. It also covers economic events that produce value that does not have a price, such as the creation of a meme. Being a digital commons, the meme lacks exchange value, but bears social value for the people using it. Within the new economic space, the producer of the meme gets rewarded for the performance of their meme, measured in terms of its virality, in tokens that account for its use value. Producers can offer stake in their activity in exchange for commodities, liquidity or stake in others' economic activity, thus sharing their risk with others and covering their basic needs. While in the external, capitalist market, such tokens may not have exchange value, they may be valued in adjunct economic spaces as input factors to economic events of higher order that are accessible only to producers and supporters of social value. In this way, economic processes that currently remain invisible as they are not reflected in capitalist price metrics are made visible and thus become formalized. Furthermore, as performances generate a multiplicity of information that can be captured as data, they allow drawing conclusions on the health of economic processes or entire spaces over time.

Economic Space Agency significantly leverages the choice of individual economic agents over the social goals their economic activity contributes to, via the risks they are willing to collectively take with others and the trust they put into others' credibility.
Core economic functions hitherto implicitly controlled by central actors are put at public disposal "as a means to enhance the way in which individual agents express their socialness." This implicitly reverses the colonization of the social by capitalist economics, as instead economic processes become expressive of social values and relations. Multi-dimensional value calculi retain a rich breadth of information within value communities while corresponding performance indices serve as information compressors aiding integration with the outside. More generally, this architecture demonstrates how economic activity can be reconceptualized as a performance, measured against arbitrarily chosen social goals, and how derivatives can be used as value membranes that enable external financial investment in such performance while preserving its internal value autonomy.

\section{SYNTHESIZING APPROACHES TO SCALING THE GLOBAL COMMONS}

As pointed out earlier, the non-capitalist or distributed socioeconomic markets envisaged by crypto-commonists differ from crypto-libertarian conceptions of markets with regards to their orientation toward aims external to the circulation of exchange value as well as their use of a non-speculative "money of the commons" that minimizes ecological costs. Interestingly, the preclusion of legal privilege of some over others, identified as a central trait of capitalist capture of markets, is eschewed by both libertarians and commonists. The projects at hand abide to these criteria to differing degrees in the conception of markets they espouse.

While all three projects inscribe external values beyond profitsharing into market interaction, they vary considerably in how they relate to commons in the physical and digital realm. The Commons Stack taxes market transactions and leaves the use of common funds to the discretion of the community, granting more flexibility vis-a-vis unforeseen events, but requires active governance. Both other projects instead inscribe external conditions into exchange value ex ante, thus allowing users to effect change by choosing appropriate currency structures for their everyday economic interactions. Holochain's Commons Engine does so through asset-backed complementary currencies that help communities track, modulate, and extend access to universal human basics as well as through non-monetary reputation currencies and impact assessment tools. While ECSA's commodity tokens are likewise asset-backed, external aims are also inscribed into economic activity more explicitly through its measurement against multi-dimensional performance indices that can be staked upon.

All three projects decentralize power over infrastructure insofar as they automate control over monetary policy and liquidity provision in accordance with closely monitored, actual economic capacity, thus removing both from the discretionary politics of central banks. For the mutual credit system used by the Commons Engine, where credits are minted and destroyed at the moment goods or services are rendered, external provision of liquidity is irrelevant and monetary policy (credit limits) are subject to collective management experiments. ECSA likewise 
renders external liquidity provision unnecessary as it allows peers to mutually issue credit against collateralized stake in performances, facilitated by a credit clearance protocol. However, credit limits are not subject to system-wide decisions but are determined decentrally by what peers accept as collateral. On the other hand, liquidity provision in the Commons Stack using bonding curves is more reminiscent of the algorithmic monetary politics of Bitcoin, which are likewise transparently inscribed into immutable code and thus entirely removed from the discretionary politics of its constituents. Notably, all approaches grant each economic participant the same potential action repertoire - including the right to issue tokens and fork and alter protocols - and thus removes any notion not only of overarching sovereign power, but also of enforced standardization beyond a shared computational foundation.

Notwithstanding these commonalities, the projects differ considerably in their stance toward speculation. The Commons Stack is the most liberal, as it actively inscribes speculative profit potential into the pricing structure of governance tokens in order to generate more traffic as a base for taxation. It furthermore remains agnostic toward the potentially speculative nature of assets accepted as collateral. Holochain-based currencies, on the other hand, are actively designed as anti-speculative as their dynamic supply is tethered to the productive capacity of the network and availability of liquidity in-kind. While ECSA's distributed offer matching and liquidity issuance enable a network of multilateral exchange that replaces the need for a centrally issued "money," its emphasis on mutual risk-taking through the exchange of stakes in the performance of economic actors likewise entails a speculative dimension marked by the trade of risk positions.

In our review of technical versus social notions of scale, we have suggested that DLT-based commons frameworks can leverage common responses to global problems through federated scaling. This form of scaling accommodates rather than obliterates heterogeneity while accounting for interlinkages and consciously shared value judgments. The permissionless issuance of tokens as well as, more generally, the modular and forkable nature of the protocols in question provide flexible infrastructure for the emergence of highly contextual communities that are value sovereign in their definition of internally shared aims. While accommodating heterogeneity, the complex interlinkages between communities require further measures to be accounted for. The case studies discussed in this article approach this challenge through mutual financial stakeholding, nested governance structures and reputation based on self-sovereign identity.

The formalization of mutual stake in tokenized assets highlights interdependencies and incentivizes cooperation between heterogeneous communities holding stake in each other. ECSA's implementation of stakeholding in the economic performance of others along mutually agreed performance indices is a generic framework that allows individuals, but also wider communities, to express commitment to common aims by sharing the risks involved in their pursuit. The Commons Stack's bonding curve likewise allows communities to formalize their interdependencies with others by accepting their governance tokens as collateral, which results in webs of nested communities that each hold stake in one another. As these governance tokens not only reflect financial stake but also grant influence in collective decision-making, such networks not only align interests but also nurture coordination through the continuous signaling of preferences enabled by Conviction Voting. While Holochain's Commons Engine does not explicitly suggest frameworks for mutual stake or governance processes, it is explicitly oriented toward making interlinked CPRs technically interoperable, so that eventually, a Holochain user/group can directly trade electricity for food, for example. The self-sovereign identity required here as a prerequisite for carrying reputation-based metrics across multiple CPRs is a crucial facet of interoperability across Holochain application spaces and creates a reliable foundation for communities' own determination of governance processes. Table 2 below examines

TABLE 2 | A comparison of the examined case studies.

\begin{tabular}{|c|c|c|c|}
\hline & Commons Stack & $\begin{array}{l}\text { Holochain's } \\
\text { Commons Engine }\end{array}$ & EcSA \\
\hline $\begin{array}{l}\text { Approach to } \\
\text { markets }\end{array}$ & $\begin{array}{l}\text { Decentralized } \\
\text { markets based on } \\
\text { offers are replaced } \\
\text { with a central, } \\
\text { automated market } \\
\text { maker }\end{array}$ & $\begin{array}{l}\text { Multiple targeted } \\
\text { currencies are supplied } \\
\text { and distributed on a } \\
\text { per-asset basis, thus } \\
\text { reflecting a dynamic } \\
\text { productive and carrying } \\
\text { capacity }\end{array}$ & $\begin{array}{l}\text { Protocolization of } \\
\text { indirect } \\
\text { matchmaking, } \\
\text { facilitated by mutual } \\
\text { credit that bridges } \\
\text { temporal } \\
\text { asynchronicity }\end{array}$ \\
\hline Speculation & Encouraged & Discouraged & Encouraged \\
\hline $\begin{array}{l}\text { Liquidity } \\
\text { provision }\end{array}$ & $\begin{array}{l}\text { algorithmic reserve } \\
\text { as automated } \\
\text { market maker }\end{array}$ & $\begin{array}{l}\text { mutual credit system } \\
\text { backed by assets as } \\
\text { collateral }\end{array}$ & $\begin{array}{l}\text { Mutual credit } \\
\text { system backed by } \\
\text { stake in } \\
\text { performances as } \\
\text { collateral }\end{array}$ \\
\hline Risk & Price risk & $\begin{array}{l}\text { Collateral default risk } \\
\text { distributed over the } \\
\text { network }\end{array}$ & $\begin{array}{l}\text { Performance risk } \\
\text { for holders of stake } \\
\text { and for creditors } \\
\text { accepting stake as } \\
\text { collateral }\end{array}$ \\
\hline $\begin{array}{l}\text { Technical } \\
\text { scaling }\end{array}$ & $\begin{array}{l}\text { Dependent on the } \\
\text { underlying DLT }\end{array}$ & $\begin{array}{l}\text { Agent centricity and } \\
\text { distributed state }\end{array}$ & $\begin{array}{l}\text { Agent centricity and } \\
\text { distributed state }\end{array}$ \\
\hline $\begin{array}{l}\text { Federated } \\
\text { social scaling }\end{array}$ & $\begin{array}{l}\text { Webs of } \\
\text { governance based } \\
\text { on nested bonding } \\
\text { curves }\end{array}$ & $\begin{array}{l}\text { Networks of reputation } \\
\text { based on self-sovereign } \\
\text { identity }\end{array}$ & $\begin{array}{l}\text { Mutual } \\
\text { stakeholding and } \\
\text { shared socio- } \\
\text { economic } \\
\text { grammars }\end{array}$ \\
\hline $\begin{array}{l}\text { Inscription of } \\
\text { external aims } \\
\text { into exchange } \\
\text { value }\end{array}$ & $\begin{array}{l}\text { ad hoc inscription } \\
\text { through dedicating } \\
\text { trade tax revenue } \\
\text { to external aims }\end{array}$ & $\begin{array}{l}\text { ex ante inscription } \\
\text { through asset- and } \\
\text { reputation-backed } \\
\text { currencies }\end{array}$ & $\begin{array}{l}\text { Explicit ex ante } \\
\text { inscription in form } \\
\text { of derivatives on } \\
\text { external aims } \\
\text { fulfillment }\end{array}$ \\
\hline $\begin{array}{l}\text { Solutions to } \\
\text { global } \\
\text { problems }\end{array}$ & $\begin{array}{l}\text { Dedicated funding } \\
\text { pools with } \\
\text { polycentric } \\
\text { governance }\end{array}$ & $\begin{array}{l}\text { Asset-backed } \\
\text { currencies reflecting } \\
\text { variable productive } \\
\text { capacity }\end{array}$ & $\begin{array}{l}\text { Internalization of } \\
\text { externalities } \\
\text { through } \\
\text { multidimensional } \\
\text { value calculi }\end{array}$ \\
\hline $\begin{array}{l}\text { Unique value } \\
\text { proposition }\end{array}$ & $\begin{array}{l}\text { Advances in } \\
\text { collective decision } \\
\text { making and } \\
\text { complex systems } \\
\text { modeling }\end{array}$ & $\begin{array}{l}\text { Visualization of } \\
\text { resource and data } \\
\text { stocks and flows as } \\
\text { currencies }\end{array}$ & $\begin{array}{l}\text { Democratize } \\
\text { finance to reconcile } \\
\text { markets with the } \\
\text { commons }\end{array}$ \\
\hline
\end{tabular}


the three case studies along a range of metrics, to summarize some of the main similarities and differences between them.

At the outset of this investigation, we noted that these projects are at least partly situated at differing levels of abstraction, take varying approaches and focus on different aspects of commoning, which results in each case study having varying strengths and blind spots. Nevertheless, each of the considered attempts to inscribe external values into market activity remains a reformist approach that piggybacks on profit-driven market exchange, reminiscent of social democratic attempts to tame capitalism through redistributive taxation while retaining profit as the driving motive of economic activity. It is only in combination that the reviewed interventions to capitalist mechanisms of accumulation can develop their full potential to incrementally transform the dominant economic paradigm into what can still only be ambiguously referred to as "post-capitalism" (Arvidsson, 2019). Such a combination is eased by the fact that both ECSA and Holochain are situated at the protocol layer, while the Commons Stack is building modules on the application layer, that is, on a higher level of the tech stack. The direct inscription of common values into the economic calculus as well as the orientation of money supply toward the variable productive capacity of different physical commons enabled by the former two projects can thus potentially be combined in fruitful ways with the more community-oriented tools the Commons Stack devises. The emerging synthesis of democratic engagement in all spheres of a commons, embedded in socioeconomic market structures consciously geared toward the shared values of its participants and mediated by money-forms that discourage extractive speculation and retain informational breadth, appears as a beacon on the otherwise gloomy horizon of capitalist realism.

\section{CONCLUSION AND FUTURE RESEARCH DIRECTIONS}

At the outset of this article, we argued that the relationship between human societies and planet Earth can be seen as oscillating between polarities of extraction and regeneration, and that the commons play a crucial role in the regenerative phases. In this context, we have further argued that the recent re-emergence of commoning is not incidental but indicative of a large-scale transition toward a more "generative" organization of society that orients its goals around the planet's global carrying capacity. Digital commons governance frameworks are of particular importance in this current historical conjuncture of accelerating rates of change threatening ecosystemic breakdown. This is because they enable scaling the organization of communities around common resources and goals to unprecedented levels of size, complexity and granularity.

Initially, digital commons and the communities producing them found themselves in a temporary alliance with a new class of "netarchical" capitalists (Bauwens, 2005), who prospered from the enablement and exploitation of participatory digital networks. The emergence of DLTs as distributed backbones for the practices of digital communities constitutes, a recognition of the hindrance of this alliance to the development of autonomy and capacity of such communities. The emergence of DLTs has already involved the creation of new spaces, grammars, leverages, tools and pathways of social and economic interaction such as universal basic services, contributory work schemes, socio-ecological accounting currencies as well as more autonomy in interdependence. All of this is made possible only through an eschewal of central intermediators extracting surplus and narrowing interaction to exploitable forms. This new generation of commons-oriented economies, protected from capture by distribution of power over infrastructure, spans not only digital but also physical production as it provides reliable organizational means to equitably produce and distribute resources in accordance with the shared values of productive communities. We introduced the notion of "federated scaling" as one way to mitigate, both technologically and socially, the tension between the need for large-scale, global cooperation demanded by the problems of our historical moment, and the commitment to egalitarian self-determination that is at the core of commoning itself.

This exploration of the frontiers of DLT-based commoning considered three cases that we deem exemplary for this new generation of commons-oriented infrastructure. While the projects differ in scope as well as in their relation to physical CPRs, they all share the task of redefining markets and money to be more conducive to the commitment to and maintenance of common value(s). This approach makes their undertaking both more risky and potentially more rewarding, as a successful redefinition of markets that retains their coordination capacity while directly pursuing social values beyond the extraction of profits constitutes the holy grail of post-capitalism. These projects diverge notably from past efforts of commons management in that they innovate upon market relations, money forms, digital identity, and governance processes to bridge to nascent post-capitalist styles, rather than oppose market relations altogether. Our discussion has highlighted the strengths of DLTs for the federated scaling of commons management tools that accommodate rather than obliterate differences by maximizing the degrees of freedom the foundational protocols of interaction leave for context-sensitive use ${ }^{27}$.

While we have provided a glance at the kinds of postcapitalist transition pathways opened up by the affordances of DLTs for commoning, we nevertheless have to caution against any deterministic interpretations: the emerging effort to "re-decentralize" the web is still struggling over the design of foundational protocols. It remains a contested political space in which diverse interests compete for adoption of

\footnotetext{
${ }^{27}$ Next to numerous attack vectors on underlying DLTs (Daian et al., 2019), which we have refrained from covering here due to their complex technical nature, the safety and liveliness of DLT-based commons can be negatively affected by the incentive structures of decentralized applications deployed on the same DLT, even if otherwise unrelated. Empirical examples thereof are high transaction fees and network congestion resulting from speculative bubbles on Ethereum in the context of the Cryptokitties hype in 2017 (Mentzer and Gough, 2018) and the immense popularization of Decentralized Finance applications in summer and autumn of 2020, which priced out transactions of lesser financial value, thus making numerous projects at least temporarily unviable. In this light, commons oriented projects are well advised to use layer two scaling solutions and more generally design their mechanisms protocol-agnostic wherever possible.
} 
vastly different interpretations of a post-corporate, distributed economy. The rift between "crypto-commonists" and "cryptolibertarians" has become more accentuated only recently, and the consequences for the development of the wider DLT environment are yet to be seen.

Just as technology itself is not neutral, academic engagement with emerging technologies is never just a "neutral" inventory thereof but always also contributes to narratives and imaginaries that impact back upon their further development. Aware of this feedback loop, we want to actively encourage further research on what we perceive as key gaps in commonist visions of DLTs as well as in academic engagement therewith: First off, the role of the state as foreseen by the architects of distributed economies has hardly received in-depth academic attention, as have the variegated reactions of states to the emergence of these economies. This is an interesting oversight in that both the crypto-libertarians, whose vision of scaling tends toward developing decentralized replacements for functions traditionally associated with the state, and crypto-commonists, who tend toward developing autonomous pockets of community resilience, each must contend with the constraints and requirements of the state jurisdictions in which they operate. The outcomes of this reckoning have substantial effects on how scaling is understood and how it proceeds in practice. Secondly, in order for a more consistent approach to commoning on DLTs to emerge, we believe that an active and structural application of theories of change to the multiple levels of intervention can provide crucial guidance and orientation through this uncharted territory. Finally, strategies will be required for the active anticipation and avoidance of inconsistencies arising from a multiplicity of heterogeneous voluntary protocols that are not necessarily wellmatched in order to harness the full potential of this exciting new class of technologies.

With the development of convivial tools and processes for collective sensemaking, social signal processing, peer-to-peer mutual credit issuance, self-sovereign identity management, reputation tracking and impact assessment - and their rapid testing and validation through simulation and modeling commons-based collaboration stands at the cusp of huge advancements in the establishment of group coherence and real time steering of our local/global institutions toward mutually beneficial outcomes. Their realization will be all the more likely if the fundamentals of scalability, in particular the interoperability of community-based structures and protocols, are forged cooperatively along holistic design principles. The ethos of intentional instantiation of collectively held values and

\section{REFERENCES}

Arvidsson, A. (2019). Capitalism and the commons. Theory Cult. Soc. 37:026327641986883. doi: 10.1177/0263276419868838

Atzori, M. (2015). Blockchain technology and decentralized governance: is the state still necessary? SSRN Electr. J. doi: 10.2139/ssrn.270 9713

Atzori, M., and Ulieru, M. (2017). Architecting the E society on blockchain: a provocation to human nature. SSRN Electr. J. doi: 10.2139/ssrn.2999715

Bauwens, M. (2005). The political economy of peer production. Post Autistic Econ. Rev. 3, 33-44. doi: 10.1002/9781119537151.ch3 cooperation applies not only to technical protocols, but also to the ways by which participation and understanding are galvanized. With novel technological means to communicate heterogeneous values, purposes and intentions, commons-oriented DLT projects have in front of them the laudable task of merging patience, care, and inclusion with leading-edge technological capacity to unlock new potential in human collaboration. Nothing short will suffice as a foundation for the fractal, interoperable, and scalable global commons that could offer massive new opportunities in dealing with pressing global challenges.

\section{AUTHOR CONTRIBUTIONS}

FF contributed to commoning as a regenerative social process, DLT-based commoning, commonist and libertarian interpretations of scale, the commons stack and ECSA contextualizations, as well as to synthesizing approaches to scaling the global commons and the conclusion. JE contributed to commoning as a regenerative social process, commons Stack and ECSA overview, synthesizing approaches to scaling the global commons and conclusion, editing, references, submission, and working group organization. EF contributed to commoning as a regenerative social process, DLT-based commoning, the holochain and commons engine overview, synthesizing approaches to scaling the global commons, and conclusion. RK contributed to commoning as a regenerative social process, commonist and libertarian interpretations of scale, research material on scaling, edits, and working group organization. SM contributed to introduction and commoning as a regenerative social process. MZ contributed research, materials and publications for citation, feedback, and direction for content. $\mathrm{MB}$ contributed to introduction and commoning as a regenerative social process. All authors contributed to the article and approved the submitted version.

\section{ACKNOWLEDGMENTS}

The authors thank Jorge Lopes and Akseli Virtanen of the Economic Space Agency for offering their insights and feedback on initial drafts, and Will Ruddick of Grassroots Economics and Sam Pospischil of ValueFlows for joining us in initial conversations. Finally, authors also thank Leanne Usher of Frontiers for her strong support and encouragement and the two reviewers for their thorough and thought-provoking feedback.

Bauwens, M., and Kostakis, V. (2014). Towards a new reconfiguration among the state, civil society and the market. J. Peer Prod. 7, 1-6. doi: 10.1007/978-1-34913571-4_1

Bauwens, M., and Pazaitis, A. (2019). "P2P accounting for planetary survival: towards a 2 p infrastructure for a socially just circular society," in Foreword by Kate Raworth. P2P Foundation. Available online at: http://commonstransition. org/p2p-accounting-for-planetary-survival/ (accessed June 27, 2019)

Beck, R. (2018). Beyond bitcoin: the rise of Blockchain World. Computer 51, 54-58. doi: 10.1109/MC.2018.1451660

Benkler, Y. (2002). Coase's penguin, or, linux and 'the nature of the firm'. Yale Law J. 112:369. doi: 10.2307/1562247 
Benkler, Y. (2006). The Wealth of Networks: How Social Production Transforms Markets and Freedom. New Haven, CT: Yale University Press.

Beverungen, A., Böhm, S., and Land, C. (2015). Free labour, social media, management: challenging marxist organization studies. Organ. Stud. 36, 473489. doi: $10.1177 / 0170840614561568$

Braga, E. (2019). "Infrastructures for future ecosystems," in Blog Entry. Available online at: https://networkcultures.org/moneylab/2019/02/25/infrastructuresfor-future-ecosystems/ (accessed January 5, 2021).

Braudel, F. (ed.). (1984). "Civilization and capitalism: 15th-18th. century," in The Perspective of the World, Vol. III (New York, NY: Harper \& Row).

Brock, A. (2017). Against the consensus on data consensus in the blockchain. email conversation. Available online at: https://wiki.p2pfoundation.net/Arthur Brock_Against_the_Consensus_on_Data_Consensus_in_the_Blockchain (accessed January 14, 2021).

Bryan, D., Lopez, J., and Virtanen, A. (2019). Crypto-Political Economy. Available online at: https://medium.com/econaut/crypto-political-economydd91c6fcff7.(accessed May 14, 2020).

Bulajewski, M. (2011). The Peer Production Illusion, Part II. Available online at: http://www.metareader.org/post/peer-production-illusion-part-2. html.(accessed September 15, 2020)

Buterin, V. (2014). A next-generation smart contract and decentralized application platform", white paper. Ethereum. Available online at: https://ethereum.org/en/ whitepaper/ (accessed January 5, 2021).

Caffentzis, G., and Federici, S. (2013). Commons against and beyond capitalism. Upping Anti 15, 83-91.

Chartier, G., and Johnson, C. W. (2012). Markets Not Capitalism: Individualist Anarchism Against Bosses, Inequality, Corporate Power, and Structural Poverty. London; New York, NY; Port Watson: Minor Compositions.

Christidis, K., and Devetsikiotis, M. (2016). Blockchains and smart contracts for the internet of things. IEEE Access 4, 2292-2303. doi: 10.1109/ACCESS.2016. 2566339

Cila, N., Ferri, G., de Waal, M., Gloerich, I., and Karpinski, T. (2020). "The blockchain and the commons: dilemmas in the design of local platforms," in Proceedings of the 2020 CHI Conference on Human Factors in Computing Systems (CHI '20). Association for Computing Machinery (New York, NY: Association for Computing Machinery), 1-14. doi: 10.1145/3313831.3376660

Coté, M., and Pybus, J. (2007). Learning to immaterial labour 2.0: my space and social networks. Ephermera 7, 88-106. doi: 10.13169/workorgalaboglob.8.1. 0088

Daian, P., Goldfeder, S., Kell, T., Li, Y., Zhao, X., Bentov, I., et al. (2019). Flash Boys 2.0: Frontrunning, Transaction Reordering, and Consensus Instability in Decentralized Exchanges. Available online at: https://arxiv.org/pdf/1904.05234. pdf.(accessed November 02, 2020).

Davidson, S., De Filippi, P., and Potts, J. (2016). Disrupting Governance: The New Institutional Economics of Distributed Ledger Technology. Available online at: http://dx.doi.org/10.2139/ssrn.2811995 (accessed January 5, 2021).

De Angelis, M. (2017). Omnia Sunt Communia: On the Commons and the Transformation to Postcapitalism. London: Verso.

De Oliveira Nunes, I., Ding, X., and Tsudik, G. (2020). On the Root of Trust Identification Problem. arxiv.org. Available online at: https://arxiv.org/abs/2010. 13858.(accessed November 02, 2020).

di Zerega, G. (2013). "Turning the tables: the pathologies and unrealized promise of libertarianism," in Uncivil Liberties: Deconstructing Libertarianism, ed. K. Georgia (New York, NY: Praxis Peace Institute), 56-112.

Ducrée, J., Etzrodt, M., Gordijn, B., Gravitt, M., Bartling, S., Walshe, R., et al. (2020). Blockchain for Organising Effective Grass-Roots Actions on a Global Commons: Saving The Planet. Available online at: https://ueaeprints.uea.ac. uk/id/eprint/75923/1/FiB_2020_Ducr_e_et_al_author_accepted_version_.pdf (accessed Augest 6, 2020).

Emmett, J., and Green, G. (2019). The Trusted Seed of the Commons Stack: Establishing Healthy Initialization Conditions for DAO Ecosystems. Available online at: https://medium.com/commonsstack/the-trusted-seed-ofthe-commons-stack-13d7e37f2de.(accessed November 02, 2020).

Emmett, J., and Zargham, M. (2019). Computer-Aided Governance (CAG) A Revolution in Automated Decision-Support Systems. The Future of DAO Governance Support via the Commons Stack. Available online at: https://medium.com/commonsstack/computer-aided-governance-cag-arevolution-in-automated-decision-support-systems-5d15aec2c3d5. (accessed May 14, 2020).
Finidori, H. (2014). An Open Source Pattern Language (re)Generative of Commons. Available online at: https://debategraph.org/Details.aspx?nid=329727 (accessed May 14, 2020).

Freund, A. (2018). Post Capital Cybernetics: A Decentralized Model for Participatory Economies and Businesses. Available online at: https://docs.google.com/ document/d/1vlOoXhHIS2hSNysH7eP44X3yP990F0zHMV_rSztQGZs/ edit\#.(accessed November 02, 2020).

Freund, A., and Stanko, D. (2018). The wolf and the caribou: coexistence of decentralized economies and competitive markets. J. Risk. Financial. Manag. 2:26. doi: $10.3390 / \mathrm{jrfm} 11020026$

Friedman, E. (2020). Internet Addiction: A Critical Psychology of Users. London: Routledge.

Fritsch, F. (2020). The Commons Stack. Realigning Incentives Towards Public Goods. Case Study. . to be published as a preprint on https://www.researchgate. net/profile/Felix_Fritsch.

Fuchs, C. (2012). "Dallas smythe today - the audience commodity, the digital labour debate, marxist political economy and critical theory. prolegomena to a digital labour theory of value," in Marx and the Political Economy of the Media, eds C. Fuchs and V. Mosco (Netherlands: Brill), 522-599.

Fuster-Morell, M. (2010). Governance of Online Creation Communities: Provision of Infrastructure for the Building of Digital Commons. Ph. D thesis, Department of Political and Social Sciences, Florence, Italy: European University Institute. doi: 10.1163/9789004291416_019

García-Siñeriz, M. P. (2018). In Blockchain They Trust - Now, Power to the People or to the Invisible Hand?. Exeter: BA Politics, Philosophy and Economics.

Garrod, J. Z. (2016). The real world of the decentralized autonomous society." triplec: communication, capitalism \& critique. Open Access J. Glob. Sustain. Inf. Soc. 14, 62-77. doi: 10.31269/triplec.v14i1.692

Gibson, J. J. (1979). The Ecological Approach to Visual Perception. Boston, MA: Houghton Mifflin.

Gismondi, M., Connelly, S., Markey, S., and Roseland, M. (eds) (2016). Scaling Up: The Convergence of Social Economy and Sustainability. Athabasca: Athabasca University Press.

Graham, S. (2020). Tokens and Goodhart's Forest. DAOs, Tokens, and Goodhart's Forest-Part 1. Available online at: https://daohaus.substack.com/p/tokensand-goodharts-forest.(accessed November 02, 2020).

Greco, T. (1994). New Money For Healthy Communities. Arizona: Thomas H. Greco, Tucson.

Hardt, M., and Negri, A. (2011). Commonwealth. Cambridge, MA: Belknap Press.

Hess, C. (2008). "Mapping the new commons," in Conference Paper, Presented at The Twelfth Biennial Conference of the International Association for the Study of the Commons (Cheltenham).

Husain, S. O., Franklin, A., and Roep, D. (2020). The political imaginaries of blockchain projects: discerning the expressions of an emerging ecosystem. Sustain. Sci. 15, 379-394. doi: 10.1007/s11625-020-00786-x

Hutchby, I. (2001). Technologies, texts and affordances. Sociology 35, 441-456. doi: $10.1177 / S 0038038501000219$

Illich, I. (1973). Tools for Conviviality. New York, NY: Harper \& Row.

Karlstrøm, H. (2014). Do libertarians dream of electric coins? The material embeddedness of bitcoin. Distinktion J. Soc. Theory 15, 23-36. doi: 10.1080/ 1600910X.2013.870083

Kostakis, V., and Giotitsas, C. (2014). "The (A)political economy of bitcoin." triplec: communication, capitalism \& critique. Open Access J. Glob. Sustain. Inf. Soc. 12, 431-440. doi: 10.31269/triplec.v12i2.606

Manski, S., and Bauwens, M. (2020). Reimagining new socio-technical economics through the application of distributed ledger technologies. Front. Blockchain 2:29. doi: $10.3389 /$ fbloc.2019.00029

Manski, S., and Manski, B. (2018). No gods, no masters, no coders? The future of sovereignty in a blockchain world. Law Critique 29, 151-162. doi: 10.1007/ s10978-018-9225-z

Marx, K. (1867/1976). Capital, Vol. I. London: Penguin.

Mentzer, K., and Gough, M. (2018). "The Impact of cryptokitties on the ethereum blockchain. conference presentation," in Proceeding of the Northeast Decision Sciences Institute 2018 Annual Conference, Providence, Providence, RI

Moore, M. L., Riddell, D., and Vocisano, D. (2015). Scaling out, scaling up, scaling deep social innovation. J. Corp. Citizensh. 58, 67-84. doi: 10.9774/gleaf.4700. 2015.ju.00009 
Motesharrei, S., Rivas, J., and Kalnay, E. (2014). Human and nature dynamics (HANDY): modeling inequality and use of resources in the collapse or sustainability of societies. Ecol. Econ. 101, 90-102. doi: 10.1016/j.ecolecon.2014. 02.014

Norman, D. A. (2004). Affordances and design. Available online at: https://www.researchgate.net/publication/265618710.(accessed May $14,2020)$

Olsson, P., Moore, M. L., Westley, F. R., and McCarthy, D. D. P. (2017). The concept of the anthropocene as a game-changer: a new context for social innovation and transformations to sustainability. Ecol. Soc. 22:31. doi: 10.5751/ ES-09310-220231

Ostrom, E. (1990). Governing The Commons: The Evolution of Institutions for Collective Action. Cambridge: University Press.

Ostrom, E. (2010). Polycentric systems for coping with collective action and global environmental change. Glob. Environ. Chang. 20, 550-557. doi: 10.1016/j. gloenvcha.2010.07.004

Ostrom, E., Burger, J., Field, C. B., Norgaard, R. B., and Policansky, D. (1999). Revisiting the commons: local lessons, global challenges. Science 284, 278-282. doi: $10.1126 /$ science.284.5412.278

Proudhon, P. J. (1851). "General idea of the revolution in the nineteenth century," in Sixth Study. Available online at: http://fair-use.org/p-j-proudhon/generalidea-of-the-revolution/ (accessed September 15, 2020)

Piques, C., and Rizos, X. (2017). "Peer to peer and the commons: a path towards transition. a matter, energy and thermodynamic perspective.” P2P Foundation. Available online at: https://commonstransition.org/wp-content/uploads/2017/ 10/Report-P2P-Thermodynamics-VOL_1-web_2.0.pdf (accessed January 5, 2021).

Rozas, D., Tenorio-Fornés, A., Díaz-Molina, S., and Hassan, S. (2018). When ostrom meets blockchain: exploring the potentials of blockchain for commons governance. SSRN Electron. J. doi: 10.2139/ssrn.3272329

Schuler, D. (2008). Liberating Voices: A Pattern Language for Communication Revolution. Cambridge, MA: MIT Press.

Singh, A., Parizi, R. M., Han, M., Dehghantanha, A., Karimipour, H., and Choo, K. K. R. (2020). "PublicBlockchains scalability: an examination of sharding and segregated witness," in Blockchain Cybersecurity, Trust and Privacy. Advances in Information Security, Vol. 79, eds K. K. Choo, A. Dehghantanha, and R. Parizi (Berlin: Springer), doi: 10.1007/978-3-030-38181-3_11

Srnicek, N., and Williams, A. (2016). Inventing the Future: Postcapitalism and a World Without Work. Brooklyn, NY: Verso.

Terranova, T. (2000). Free labour. producing culture for the digital economy. Soc. Text 18, 33-57.

Turchin, P., and Nefedov, S. A. (2009). Secular Cycles. Princeton, NJ: Princeton University Press.

Ulieru, M. (2016). "Blockchain 2.0 and beyond: adhocracies," in Banking Beyond Banks and Money. New Economic Windows, eds P. Tasca, T. Aste, L. Pelizzon, and N. Perony (Berlin: Springer), doi: 10.1007/978-3-319-42448-4_15

Volont, L., and Van Andel, W. (2018). "Blockchain: tragedy in cyberspace? How the commoner could benefit from the free-rider," in Commonism: A
New Aesthetic of the Real, eds N. Dockx and P. Gielen (Amsterdam: Valiz), 237-249.

von Foerster, H. (1995/1974). Cybernetics of Cybernetics: Or, the Control of Control and the Communication of Communication, 2nd Edn. Minneapolis, MN: Future Systems.

Voshmgir, S. (2020). "Purpose Driven Tokens," in Token Economy: How Web3 Reinvents the Internet, 2 Edn, ed. P. Prophet (Berlin: BlockchainHub Berlin), 266-274.

Voshmgir, S., and Zargham, M. (2019). "Foundations of cryptoeconomic systems," in Vienna University of Economics. Cryptoeconomics Working Paper Series. Available online at: https://epub.wu.ac.at/7309/8/Foundations\%20of\% 20Cryptoeconomic\%20Systems.pdf.(accessed May 14, 2020).

Weber, L. G. (2017). Gentrifying the Commons. Available online at: https:// artseverywhere.ca/2017/05/25/gentrifying-the-commons/.(accessed September $15,2020)$.

Whitaker, M. D. (2009). Ecological Revolution: The Political Origins of Environmental Degradation and the Environmental Origins of Axial Religions. China, Japan, Europe. Cologne: Lambert Academic Publishing.

Zargham, M. (2019). Exploring Subjectivity in Algorithms. Available online at: https://medium.com/sourcecred/exploring-subjectivity-in-algorithms5d8bf1c91714.(accessed November 02, 2020).

Zargham, M., de Fillipi, P., Tan, J., and Emmett, J. (2020a). Exploring DAOs as a New Kind of Institution: A Dialogue Between the Metagovernance Project and the Commons Stack. Available online at: https://medium.com/commonsstack/ exploring-daos-as-a-new-kind-of-institution-8103e6b156d4.(accessed May 14, 2020).

Zargham, M., Shorish, J., and Paruch, K. (2020b). From curved bonding to configuration spaces. IEEE ICBC 2020, 1-3. doi: 10.1017/9781139507677.002

Zargham, M., Shorish, J., and Paruch, K. (2020c). "Economic games as estimators," in Proceeding of the 2nd International Conference on Mathematical Research for Blockchain Economy (MARBLE). Vilamoura, Portugal, 2020, eds P. Pardaios, I. Kotsireas, Y. Guo, and W. Knottenbelt (Cham: Springer International Publishing) doi: 10.1016/0899-8256(89)90002-x

Conflict of Interest: JE and MZ were employed by BlockScience. EF was employed by Commons Engine.

The remaining authors declare that the research was conducted in the absence of any commercial or financial relationships that could be construed as a potential conflict of interest.

Copyright (c) 2021 Fritsch, Emmett, Friedman, Kranjc, Manski, Zargham and Bauwens. This is an open-access article distributed under the terms of the Creative Commons Attribution License (CC BY). The use, distribution or reproduction in other forums is permitted, provided the original author(s) and the copyright owner(s) are credited and that the original publication in this journal is cited, in accordance with accepted academic practice. No use, distribution or reproduction is permitted which does not comply with these terms. 